\title{
El dolo como adscripción de conocimiento*
}

\section{Die Vorsatz als Zuschreibung von Wissen}

\section{The intent as ascription of knowledge}

\author{
Nicolás Oxman \\ Profesor de Derecho Penal \\ Universidad Central de Chile \\ nicolas.oxman@ucentral.cl
}

\section{Resumen}

El presente artículo aborda desde la filosofía del lenguaje la posibilidad de establecer reglas prácticas para la imputación a título de dolo en el Derecho Penal. Se describe el uso adscriptivo del lenguaje en sentido institucional. Al mismo tiempo, se desarrollan las diferencias que tiene esta tesis con otras posturas elaboradas por la dogmática penal. Finalmente, se expone cómo la teoría del lenguaje puede explicar la objetivación del contenido de la imputación a título de dolo y la renuncia a la valoración de lo mental.

Palabras clave: imputación subjetiva, filosofía del lenguaje, dolo.

\section{Zusammenfassung}

Der vorliegende Artikel beruht auf die Möglichkeit, praktische Regeln für die Beschuldigung eines Vorsatzes im Rahmen des Strafrechts aufstellen zu können, mit der Nutzung der Sprachphilosophie. Es wird der askriptiver Sprachgebrauch im institutionellen Sinne. Es werden ebenso die Unterschiede zwischen dieser These und anderen Ansichtspunkte der Strafrechtsdogmatik illustriert. Schließlich wird es verdeutlicht, wie die Sprachtheorie die Objektivität des Inhaltes der Zuschreibung des Vorsatzes und den Verzicht der Wertschätzung des Geistiges erklären kann.

Stichworte: Subjektive Zurechnung, Sprachphilosophie, Vorsatz.

\begin{abstract}
This article analyzes the possibility of establishing practical rules for the imputation of intention in the Criminal Law using the philosophy of language framework. To achieve that

\footnotetext{
* El presente artículo fue concluído en una breve estancia de investigación en el Departamento de Derecho Penal de la Universidad de Valencia en el mes de septiembre de 2018, ocasión en que pude recopilar el material bibliográfico necesario para terminar el texto con la gentil y especial ayuda de los profesores doctores Lucía Martínez Garay, Tàlia González Collantes, Ángela Matallín Evangelio, José Luis González Cussac, Emiliano Borja Jiménez, Alberto Alonso Rimo y César Chaves. También, quisiera agradecer la colaboración del profesor doctor Marcelo Hadwa Issa tanto por la correción de la versión final como por sus valiosas aportaciones críticas.
} 
goal, the article describes the ascriptive use of language in the institutional sense. At the same time, this article highlights the differences that this thesis has with alternative positions elaborated by Criminal Law scholars. Finally, it is exposed how the theory of language can explain the objectivation of the content of the imputation of intent and the renunciation of the valuation of the mental states.

Keywords: subjective imputation, philosophy of language, intention.

\section{Introducción}

En la dogmática penal es todavía objeto de discusión el contenido conceptual del dolo, ${ }^{1}$ su ubicación dentro del sistema de la teoría del delito, ${ }^{2}$ los límites que permiten diferenciarlo de la imprudencia ${ }^{3}$ y la prueba de sus elementos. ${ }^{4}$ El debate doctrinal actual, se caracteriza por una serie de trabajos impulsados desde el creciente auge de las concepciones analíticas y neohegelianas, las que han venido a plantear, desde las teorías del lenguaje y la teoría de las normas, la necesidad de ir en la búsqueda de un nuevo metaconcepto de dolo, ${ }^{5}$ o bien, de ningún concepto sino de las condiciones o reglas que permitan atribuir distintas clases, tipos o niveles de conocimiento. ${ }^{6}$

En efecto, el estado actual de la teoría del delito se caracteriza por el abandono progresivo de la noción de injusto personal, ${ }^{7}$ al cual pertenece la idea de un dolo natural enunciado

\footnotetext{
1 Así, JAKOBS, Günther, “Altes und Neues zum strafrechtlichen Vorsatzabegriff”, Rechtswissenschaft, 3 (2010), pp. 282-297, passim. MIRÓ LLINARES, Fernando, "Dolo y derecho penal empresarial: debates eternos, problemas modernos”, Cuadernos de Política Criminal, 113 (2014), pp. 201-252, pp. 203 y ss.

${ }^{2}$ Así, MOLINA, Fernando, "El razonable regreso del dolo a la culpabilidad”, en: SILVA SÁNCHEZ, Jesús María, et al. (Coords.), Estudios de Derecho penal. Libro homenaje al profesor Santiago Mir Puig, Montevideo-Buenos Aires: B de F, 2017, 735-751, passim. También, MORILLAS CUEVA, Lorenzo, "De nuevo sobre la doble posición del dolo y de la imprudencia”, en: SILVA SÁNCHEZ, Jesús María, et al. (Coords.), Estudios de Derecho penal. Libro homenaje al profesor Santiago Mir Puig, Montevideo-Buenos Aires: B de F, 2017, pp. 753-767, passim.

3 PUPPE, Ingeborg, "La imputación del resultado al dolo" en: SILVA SÁNCHEZ, Jesús María, et al. (Coords.), Estudios de Derecho penal. Libro homenaje al profesor Santiago Mir Puig, Montevideo-Buenos Aires: B de F, 2017, pp. 803-813, passim. En especial, en relación con el dolo eventual como límite mínimo. PUPPE, Ingeborg, El Derecho penal como ciencia. Método, teoría del delito, tipicidad y justificación, Montevideo-Buenos Aires: B de F, 2014, pp. 219-314

4 SÁNCHEZ-VERA GÓMEZ TRELLES, Javier, "Un reto para el dolo: los motivos del autor", en: MAQUEDA ABREU, María Luisa; MARTÍN LORENZO, María; VENTURA PÜSCHEL, Arturo (Coords.), Derecho penal para un Estado Social y Democrático de Derecho. Estudios penales en homenaje al profesor Emilio Octavio de Toledo y Ubieto, Madrid: Servicio de Publicaciones de la Facultad de Derecho de la Universidad Complutense de Madrid, 2016, pp. 339-363, passim.

${ }^{5}$ PÉREZ BARBERÁ, Gabriel, El dolo eventual. Hacia el abandono de la idea del dolo como estado mental, Buenos Aires: Hamurabi, 2010, pp. 85 y ss. PORCIÚNCULA, José Carlos, Lo “objetivo” y lo "subjetivo” en el tipo penal. Hacia la "exteriorización de lo interno", Barcelona: Atelier, 2014, pp. 177 y ss.

${ }^{6}$ FERREIRA CABRAL, Rodrigo, Dolo y lenguaje. Hacía una nueva gramática del dolo desde la filosofía del lenguaje, Valencia: Tirant lo Blanch, 2017, pp. 211 y ss., PORCIÚNCULA, Lo “objetivo”, cit. nota n⿳ 5, pp. 301 y ss. SÁNCHEZ MÁLAGA, Armando, Una teoría para la determinación del dolo. Premisas teóricas e indicadores prácticos, Montevideo-Buenos Aires: B de F, 2018, pp. 395-430.

${ }^{7}$ Así, por ejemplo, SILVA SÁNCHEZ, Jesús María, “¿Adiós a un concepto unitario de injusto en la teoría del delito? A la vez, una breve contribución a la teoría de las medidas de seguridad”, InDret, 3 (2014), pp. 1-21, pp. 2-4.
} 


\section{Polít. Crim. Vol. 14, № 28 (Diciembre 2019), Art. 12, pp. 441-467 \\ [http://politcrim.com/wp-content/uploads/2019/12/Vol14N28A12.pdf]}

bajo la fórmula académica "conocimiento y voluntad de los elementos del tipo". ${ }^{8}$ En contra de tal postulado, se plantean variantes como el dolo indirecto ${ }^{9}$ o el regreso al dolus malus, ${ }^{10}$ posiciones doctrinales cuyo punto de encuentro es el rechazo generalizado al lugar central que ha ocupado el elemento volitivo del dolo, en especial, a las teorías de la voluntad, del consentimiento y la aceptación, que posibilitaban la conceptualización del dolo eventual como una manifestación de un concreto nivel de voluntad. En su remplazo, se postula una sola forma de dolo: el dolo como conocimiento, perspectiva que reclama, por cierto, la necesidad de establecer criterios que permitan comprender y objetivar los fundamentos o las reglas que sirven para imputar ese conocimiento, cuestión que este trabajo aborda desde la filosofía del lenguaje. A partir del uso adscriptivo del mismo se ofrece una posibilidad de comprensión de los comportamientos en relación con las normas, punto de partida que podría ser utilizado para la afirmación posterior de la imputación de distintas clases de conocimiento en el proceso penal. ${ }^{11}$

\section{El uso adscriptivo del lenguaje}

Siguiendo a Austin ${ }^{12}$ decir algo en relación con una acción, por ejemplo: " $A$ mató a $B$ ” no es simplemente enunciar algo; no se trata de una proposición descriptiva, sino que "decir algo es hacer algo", en otros términos, equivaldría no a enunciar la descripción de una acción, sino que al decir que $A$ ejecutó la acción de matar a $B$, tiene lugar un acto realizativo y adscriptivo de responsabilidad.

Esta idea fue desarrollada en relación a la teoría del lenguaje y su vinculación con la responsabilidad por Hart, ${ }^{13}$ para quien, a partir de las funciones que desempeña el lenguaje ordinario en relación con las acciones, era posible distinguir entre, por un lado, el uso descriptivo del lenguaje referido a cosas, eventos o personas $\mathrm{y}$, por otro lado, el uso

\footnotetext{
8 "Wissen (conocimiento) und Wollen (voluntad)", es una fórmula calificada como una imprecisión lingüística. Así, WESSELS, Johannes; BEULKE, Werner; SATZGER, Helmut, Strafrecht Allgemeiner Teil. Die Straftat un ihr Aufbau, 44. Auflage, Heidelberg, München: C. F. Müller, 2013, número marginal 202-203, p. 91. A fin de matizar su afiliación a una postura dogmática determinada (en concreto, la heredada del finalismo), se dice que se trata de un metaconcepto "con fines académicos", JAKOBS, "Altes und Neues", cit. nota $\mathrm{n}^{\circ} 1$, p. 282.

9 JAKOBS, "Altes und Neues", cit. nota $\mathrm{n}^{\circ}$ 1, p. 306. HSU, Yu-An, "Indiferencia como dolo indirecto", en: MONTEALEGRE, Eduardo; CARO, José Antonio (Ed.), El sistema penal normativista en el mundo contemporáneo, Libro Homenaje a Günther Jakobs, Bogotá: Universidad Externado de Colombia, 2008, pp. 411-440, pp. 418-420.

${ }^{10}$ El dolo completo requiere, para los partidarios de esta tesis, la conciencia de la antijuridicidad, distinguiendo tres niveles de dolo: el dolo típico (conocimiento y voluntad), el dolo típico en referencia a los presupuestos de una causa de justificación y el dolo completo, que supone la conciencia de la antijuridicidad, que equivale al dolus malus y que es presupuesto de la imputación personal de la antijuridicidad penal, FAKHOURI GÓMEZ, Yamila, Delimitación entre error de tipo y de prohibición. Las remisiones normativas: un caso problemático, Pamplona: Thomson Reuters, 2009, p. 454.

${ }^{11}$ En extenso, sobre las distintas clases de conocimiento, VARELA, Lorena, Dolo y error. Una propuesta para la imputación auténticamente subjetiva, Barcelona: Bosch, 2016, pp. 269-323.

${ }^{12}$ En especial, la segunda conferencia. AUSTIN, J. L. How to do things with words, The William James Lectures delivered at Harvard University in 1955, Oxford: Clarendon Press, 1962, pp. 12-13.

${ }^{13}$ HART, H. L. A. "The Ascription of Responsibility and Rights", Proceedings of the Aristotelian Society New Series, Vol. 49, (1948-1949), pp. 171-194, passim.
} 
adscriptivo del modo enunciativo de responsabilidad: "él lo hizo", "tú lo hiciste", "lo hice”, que estaría más allá de la preliminar descripción causal de una acción.

De este modo, la adscripción o imputación de una conducta a su autor a través de una oración enunciativa de responsabilidad sería una afirmación sujeta a la objeción de verificación, esto es, sería defensable ("defeasible”) o derrotable ${ }^{14}$ por la concurrencia de un permiso fuerte o débil.

Este es, sin duda, la descripción del lenguaje característico de la imputación materializada en el proceso penal, en la medida en que la acusación y la sentencia enuncian conductas que se ponen en relación con el lenguaje prescriptivo de las normas penales a través de la adscripción de responsabilidad que denota en una oración del modo: " $A$ mató a $B$ ", " $A$ abusó sexualmente de $B$ ”, “ $A$ estafó a $B$ ”, etc.

Lo anterior, no es otra cosa que el resultado de la sintaxis lógico-práctica (un silogismo práctico) que supone poner la acción ${ }^{15}$ en relación con el lenguaje ordinario y las normas penales. Este proceso, se materializa de un modo característico en los procesos judiciales: es el resultado, según afirmaba Hart, de una ponderación entre los hechos probados y su vinculación con las normas jurídicas. ${ }^{16}$

En la praxis es en la acusación donde, sobre la base de la interpretación de reglas prácticas de acción, se formula en lo que al aspecto subjetivo de la imputación se refiere, enunciados adscriptivos del tipo: " $A$ mató intencionalmente a $B$ ". Sin embargo, ello no implica atribución de antinormatividad y, tampoco, conlleva la afirmación de la culpabilidad, porque, como decíamos, se trata de una atribución de realización de acciones intencionales

\footnotetext{
${ }^{14}$ Esta parece ser la traducción más literal del término y tal como ocurre en ingles no hay una palabra en el lenguaje ordinario que sirva para identificar este concepto en oposición a las razones indefeasibles de la lógica deductivista.

15 ANSCOMBE, G. E. M. "Intention”, Proceedings of the Aristotelian Society, New Series, Vol. 57 (19561957), pp. 321-332, p. 332.

${ }^{16}$ Incluso en la ponderación argumentativa propia de la filosofía del lenguaje, no parecen ser tan claras las objeciones que los teóricos de la acción y del lenguaje formularon con posterioridad a la aparición de the adscription of responsability and rights. En especial, la crítica formulada por quienes defendían una visión puramente cartesiana de la mente y la importancia del contenido de la voluntad como causa de los movimientos corporales. GEACH, P. “Ascriptivism”, The Philosophical Review, Vol. 69:2 (1960), pp. 221225, passim. Ahora bien, Hart reculó parcialmente de su postura, en la medida que sostuvo que las objeciones le parecían "atendibles". HART H. L. A. "Punishment and Responsibility", Essays in the Philosophy of Law, $2^{\mathrm{a}}$ ed., Oxford: Oxford University Press, 2008, p. 5. Al respecto, la aportación de Davidson en este sentido, esto es, la idea que toda acción supone una razón para la acción, con independencia de la interpretación que podamos hacer de esa acción, parece haber sido uno de los puntos por los cuales Hart habría abandonado, aunque no totalmente su original idea, según se desprende -dice Feinberg- de Causation in the Law. Al respecto, FEINBERG, Joel, "Action and responsibility", Essays in Theory of Responsibility, Princeton: University Press, 1970, p. 149. A lo que Feinberg se refiere es la forma en que Honoré y Hart conceptualizan el proceso de atribución de la causalidad, a la crítica que realizan de las teorías clásicas de la condictio sine qua non, a la circunstancia que tomen como punto de partida la idea de causalidad desde el lenguaje ordinario, la distinción entre razón y causa, todo ello con claras referencias a la idea de objetivación de la valoración desde la tercera persona; aunque en lo relativo al fundamento e intensidad del reproche moral, tomaron como referencia la distinción entre acciones voluntarias y no voluntarias. HART, H.L.A; HONORÉ, Tony, Causation in the Law, $2^{\mathrm{a}}$ ed., Oxford: Clarendon Press, 1985, pp. 136 y ss.
} 


\section{Polít. Crim. Vol. 14, № 28 (Diciembre 2019), Art. 12, pp. 441-467 \\ [http://politcrim.com/wp-content/uploads/2019/12/Vol14N28A12.pdf]}

"derrotable" en el curso del proceso penal (entendido como curso o dinámica de la práctica de imputar).

En efecto, la derrotabilidad de un enunciado adscriptivo por el cual se atribuye intencionalidad (como resultado de un proceso de interpretación lógica realizada ex post por un tercero sobre el comportamiento de otro), puede devenir por la falta de acreditación del suceso o por la prueba negativa de la participación y, en especial, porque pese a que las circunstancias que fundamentan "el hecho" están "presentes" y puedan ser "verificables", concurre alguna defensa o excusa que excluye la posibilidad de la pena, o bien, disminuye la intensidad o medida de la imposición de la sanción por el quebrantamiento doloso de normas penales.

De ahí, que el enunciado adscriptivo " $A$ mató a $B$ ”, puesto en relación con la prescripción normativa "el que mate a otro" signifique que " $A$ ha cometido un homicidio a menos que concurra una defensa o una excusa". Y es evidente que en la caracterización de cualquier delito están presentes el concepto y un cúmulo de heterogéneas circunstancias que legalmente sirven para "derrotar" la afirmación según la cual es posible, en un caso concreto, afirmar que un determinado suceso o acontecimiento, reconocible o subsumible en una norma penal puede ser interpretado como una obra del autor.

Así, el adscriptivismo de Hart tuvo como mérito el asignarle a la acción una función operativa de carácter negativo (derrotable) que conllevó una objetivación de su contenido y una superación de las teorías tradicionales acerca de la conducta humana. ${ }^{17}$ En este sentido, el adscriptivismo planteaba abandonar las cuestiones metafísicas ligadas a la libertad de la voluntad, en especial, la teorización con pretensiones filosóficas sobre determinismo e indeterminismo. Y, con ello, postulaba que el objeto de estudio debía estar en la creación de reglas prácticas orientadas a la construcción y comprensión racional de la acción imputable, a partir de la pregunta sobre si en el caso concreto puede o no adscribirse o imputarse a un sujeto una acción en la medida que significa el quebrantamiento con conocimiento del contenido de las reglas del lenguaje ordinario expresada preliminarmente en una norma. Al mismo tiempo, la afirmación de haber obrado dolosamente contenida en la acusación solo adquiriría significado en la medida que sea puesta en relación con la prueba de los acontecimientos prácticos que la sustentan. En suma, la adscripción de intencionalidad es el resultado de un proceso que reconstruye la acción sobre la base de un acontecimiento reinterpretable, a partir del conocimiento que nosotros tenemos de las acciones. ${ }^{18}$

Lo rescatable de la versión original del adscriptivismo es que pretendía desterrar por completo la prueba de la voluntad entendida como un "querer" asociado a la intención como nivel subjetivo necesario para la imputación de acciones en el proceso penal ${ }^{19}$. Al

\footnotetext{
17 "The principal field where jurists have, I think created difficulties for themselves (in part under the influence of the traditional philosophical analysis of action) by ignoring the essentially defeasible character of the concepts they seek to clarify is the Criminal Law". HART, "The Ascription", cit. nota n 13, p. 179.

${ }^{18}$ HART, "The Ascription", cit. nota no 13, p. 180.

${ }^{19}$ Claramente, Hart tomó la distinción que realizara Aristóteles sobre las acciones que son merecedoras de reproche moral. Así, mientras las acciones voluntarias son las que tiene por objeto aprobación o reproche, las involuntarias son aquellas que son objeto de indulgencia. Estas últimas, en un primer momento, podrían aparecer como voluntarias porque al realizarse serían objeto de una elección, pero el fin de la acción
} 
mismo tiempo, en la tesis original la voluntariedad de las acciones es claramente distinguible de la intencionalidad de nuestras acciones; ${ }^{20}$ sin perjuicio que ambas están sujetas al proceso valorativo de adscripción en sede de la tercera persona tomando como referencia el lenguaje ordinario, según veremos infra.

\section{Adscripción o imputación en sentido institucional}

El afirmar que una persona realizó una acción dolosa solo tiene sentido si ello se valora en un contexto institucional que no es otro lugar que el proceso penal, donde un tercero (el juez) tiene el deber de establecer una correspondencia entre una acción, un sujeto y las normas de prohibición o mandato como paso previo a las consecuencias que ello puede implicar (penas o medidas de seguridad). En este contexto, el adscriptivismo sostiene que el afirmar en el proceso penal que alguien realizó una acción dolosa no es un tipo de enunciado de culpabilidad, pero sí conlleva una afirmación preliminar de antinormatividad. Si esto es así, decir que $A$ mató intencionalmente a $B$, es una afirmación derrotable por la presencia de permisos fuertes o débiles (en otros términos, por la presencia de una justificación o de excusas).

Ahora bien, sostener que $A$ mató a $B$ dolosamente, solo supone, según lo indicado, plantear un silogismo práctico que afirma un supuesto básico de acción, interpretado como la contravención "intencional" de una regla. En el contexto institucional del proceso penal, lo anterior no es una cuestión puramente descriptiva, sino que constituye un enunciado performativo sobre la realización de una acción en relación con normas jurídicas: enuncia así, preliminarmente, la presencia de un ilícito contrario a una norma (antijurídico), con independencia de la valoración posterior que resulta de la concurrencia de una defensa o una excusa. Con ello, se quiere expresar, conforme a Austin que, en determinados contextos, "decir algo" equivale a una expresión verbal indicativa de un enunciado perfomativo de una acción, esto es, que no es considerada normalmente como "solo decir algo". 21

dependería del momento; tales acciones recibían para Aristóteles el nombre de acciones mixtas, porque en un principio aparecen como reprochables moralmente, pero después pueden ser objeto de alabanza o perdón. El ejemplo es del sujeto que arroja la carga del barco en la tempestad para alivianar el peso. Así, una acción en principio censurable aparece, en un segundo momento, como un acto sensato en la medida que tal atribución aparece como derrotada por una excusa. ARISTÓTELES, Ética Nicomáquea, PALLÍ BONET, J. (trad.), Madrid: Gredos, 2011, III, I, 1109b, 30, 1110a, 1-20.

${ }^{20}$ Así en ARISTÓTELES, Ética Nicomáquea, III, I, 1111b, 25. Esta idea, subsiste en la elaboración de la teoría del delito, con independencia de la sistemática que se adopte. Así, por ejemplo, "el uso normal de la expresión voluntaria, aplicada a una acción, no hace referencia a una relación psicológica, sino a una relación de atribuibilidad. Decimos que alguien hizo algo voluntariamente cuando se le puede atribuir lo que hizo, esto es, cuando se le puede premiar o castigar por ello". COBO DEL ROSAL, Manuel; VIVES ANTÓN, Tomás, Derecho Penal. Parte General, $5^{\text {a }}$ ed., Valencia: Tirant lo Blanch, 1999, pp. 554-555. Y, por cierto, como indicara Hruschka: "every imputation to merit or demerit implies the preceding application of a law to a deed. The latter implies first level imputation of that deed and the determination that the individual was the free cause thereof"; "the problem of freedom cannot be avoided by merely maintaining that imputation only implies freedom of spontaneity. The epileptic who breaks a window during a seizure cannot be imputed (ordinarily) with this occurrence as a deed. The event, therefore, cannot be viewed as a violation of duty and blameworthy even though property was damaged", HRUSCHKA, Joachim, "Imputation", BYU Law Review, 3 (1986), p. 704.

${ }^{21}$ AUSTIN, How to do, cit. nota no 12, pp. 6-7. 
Así, dado que decir que $A$ ejecutó una acción con la "intencionalidad" subjetiva suficiente para motivar un contexto institucional como un proceso penal, ello puede suponer la enunciación de una declaración de antinormatividad, en la medida que solo interesan al proceso penal acciones con significado jurídico-penal; es la adscripción o imputación de acciones, que no es ni falsa ni verdadera, sino que solo derrotable. ${ }^{22}$

Las expresiones relativas a la concurrencia de intencionalidad vertidas comúnmente en las sentencias no son puramente descriptivas. En la medida que, junto con indicar las circunstancias en que ha tenido lugar la acción, es común que agreguen uno o más verbos de acción (por ejemplo, "asestar", "golpear", "herir", etc.) que, al estar referidos a un acontecimiento pasado, adquieren en relación con el lenguaje y las normas penales un sentido adscriptivo (“ $A$ asesinó dolosamente a $B$ ”).

Así, la descripción " $A$ asestó a $B$ cinco cuchilladas por la espalda", presupone o habilita el acto del habla performativo que suele expresarse dentro de la argumentación de las sentencias penales, al modo adscriptivo: "A realizó un homicidio doloso". Este uso del lenguaje en las sentencias implica, en cuanto a la atribución de conocimiento, referencialidad. ${ }^{23}$ Ello en la medida que solo cobra sentido para nosotros porque entendemos que conlleva la atribución de realización de una acción interpretada como una infracción a la comprensión del contenido de la prohibición o el mandato establecido en una norma penal.

En este contexto, la forma en que se entiende concurrente el dolo en el lenguaje adscriptivo sirve para elaborar reglas operativas para la imputación de conocimiento a partir de su propia pragmática, es decir, para establecer qué acciones, en un supuesto de hecho concreto, pueden ser interpretadas por nosotros con un significado intencional (doloso). ${ }^{24}$

\footnotetext{
${ }^{22}$ Austin describe los enunciados performativos como una forma de hablar o escribir que, en sentido formal, contienen una declaración asertiva expresiva de un sentido (o no es un sinsentido), que no es verdadera o falsa; expresadas en un verbo conjugado en primera persona singular que, además, al pronunciarse en determinados contextos institucionales conlleva que "decir" sea "hacer". Al respecto, da como ejemplo el matrimonio, donde los contrayentes pronuncian las palabras "yo, te acepto como cónyuge", o bien, el bautizo del barco Reina Isabel II, donde pronunciar las palabras: "el nombre de este barco será...", equivale a bautizar el barco en el contexto de la ceremonia. A diferencia, de otros enunciados que conllevan el uso de la forma indicativa condicional del verbo poder ("podría") o su forma indicativa presente ("puede"). AUSTIN, J. L. Philosophical Papers, Oxford: Clarendon Press, 1961, p. 222.

${ }^{23}$ SEARLE, John, Intencionalidad. Un Ensayo en la Filosofía de la Mente, UJALDÓN; VALDÉS (trad.), Madrid: Tecnos, 1992, pp. 39 y ss. En otros términos, cuando se habla de "intencionalidad" en el presente trabajo no se está haciendo referencia a los casos abarcados por el "querer" (will); la intencionalidad como explicara Austin no implica volición, aunque pueda estar relacionada con ella, se trata de la interpretación del significado de un evento o acontecimiento conforme a una norma de prohibición. Lo que debe diferenciarse a su vez del supuesto en que junto a la ausencia de "querer" falta también la "intencionalidad" pero el evento puede ser interpretado como el incumplimiento de un deber de cuidado (negligencia o imprudencia). Al respecto, AUSTIN, John, Lectures on Jurisprudence. The Philosophy of Positive Law, New York: Henry Holt and Company, 1875, p. 200.

${ }^{24}$ Un concepto "analítico" no denota una clase cerrada de enunciados como es común en las definiciones de la dogmática penal, en la medida que estas suelen ser utilizadas con pretensiones de transformarse en fórmulas abreviadas generalizadoras y con elementos específicos, al modo de una lista de elementos. Se trata de proposiciones que sin referencia a la realidad que las han originado carecen de sentido, como ocurre con las
} 
En otros términos, se trata de elucidar el concepto de dolo a través de su gramática profunda ${ }^{25}$ es transformar un concepto abstracto con pretensión de generalización y, por ende, inexacto en otro aclaratorio a través del reconocimiento de las reglas derivadas del uso lenguaje. Preliminarmente, la búsqueda de un concepto analítico de dolo supone, establecer su definición desde el lenguaje ordinario. En otras palabras, es la pregunta sobre qué diría o cómo se referiría al dolo alguien que ignorase por completo el contexto en que es utilizada esta expresión en el sistema penal. ${ }^{26}$

Pues bien, hemos visto antes que las normas penales se interpretan conforme a las reglas del lenguaje, esto quiere decir que quien realiza el proceso de adscripción conoce una serie de reglas sociales que determinan el comportamiento que es esperable o tolerable, conforme a la observación de otras conductas o actos. Ello se debe, sin duda, a la circunstancia que solo a través del lenguaje se toma parte en conductas humanas que están gobernadas por reglas y "aprender y dominar el lenguaje es, entre otras cosas, aprender y haber dominado esas reglas". ${ }^{27}$

Ahora bien, por el momento, volviendo a Austin habría que preguntarse: ¿es un tipo de acto del habla la adscripción de acciones a título de dolo que realiza el juez en una sentencia penal?

Una posible respuesta es entender que el enunciado: "A obró dolosamente" (a) no solo implica describir en esta perspectiva un estado de cosas, sino que también presupone el poder de conferir reglas sobre la interpretación de la concurrencia del dolo (b). Sin embargo, (a) no consiste en un acto del habla performativo, pero sí está sujeto en cambio a reglas interpretativas que determinan el modo en que es posible atribuirle a un sujeto (a) en cuanto estado de cosas. En suma, (a) cumple la función de enunciado operativo para la atribución de acciones en relación con normas penales. Con todo, tal como ocurre con los actos del habla, para poder pronunciar las palabras del enunciado (a) es preciso interpretar las acciones conforme al lenguaje ordinario y sus reglas. Y, finalmente, se debe tener también el poder jurídico de conferir una regla sobre el sentido de las normas que describen

fórmulas de las ciencias exactas. Por el contrario, parece ser que un concepto analítico es una generalidad surgida desde el lenguaje ordinario con capacidad de proyección dinámica en relación con nuevos casos. SEARLE, Intencionalidad, cit. nota $\mathrm{n}^{\mathrm{o}} 23$, pp. 17 y ss.

${ }^{25}$ En general, es posible asociar palabras como símbolos expresivos de conceptos, esto ocurre con regularidad con las categorías de la teoría del delito (dolo, imprudencia, caso fortuito, imputabilidad, etc.), sería una relación asociativa (en términos psicológicos) donde únicamente a través de la palabra podemos notar un símbolo (gramática superficial). Sin embargo, entender las palabras como proposiciones que expresan términos relacionados a través de la lógica o de las reglas relativas al uso correcto de las palabras que adquieren significado a través de los juegos del lenguaje ordinario, lo que importa denotar un símbolo (gramática profunda). Sobre esta distinción de notar y denotar, RUSSELL, Bertrand, "V. Denotación", Los Principios de la Matemática. Ciencia y Filosofía (1897-1919), Obras Completas, t. II., Madrid: Aguilar, 1973, pp. 436-446.

${ }^{26}$ En relación con los fundamentos sobre los cuales se construye esta afirmación, SEARLE, Intencionalidad, cit. nota $n^{\mathbf{0}} 23$, p. 15 .

27 "Mi conocimiento de cómo hablar un lenguaje incluye el dominio de un sistema de reglas que hace que mi uso de los elementos de ese lenguaje sea regular y sistemático. Reflexionando sobre mi uso de los elementos del lenguaje puedo llegar a conocer los hechos que registran las caracterizaciones lingüísticas". SEARLE, Intencionalidad, cit. nota $\mathrm{n}^{\mathrm{o}} 23$, pp. 22 y 23. 


\section{Polít. Crim. Vol. 14, № 28 (Diciembre 2019), Art. 12, pp. 441-467 \\ [http://politcrim.com/wp-content/uploads/2019/12/Vol14N28A12.pdf]}

contravenciones entendidas, en sentido amplio, como la prohibición o el mandato de no incurrir en (a) en cuanto estado de cosas. La síntesis del proceso se traduce en la adscripción derrotable de acciones, consideradas como la contravención de normas jurídico-penales.

De este modo, cuando el juez dice en la parte considerativa de la sentencia que el acusado obró dolosamente, conforme a la prueba de cargo, utiliza un enunciado puramente operativo $^{28}$ del acto del habla performativo que supone la declaración posterior de responsabilidad penal en la sentencia condenatoria bajo la fórmula: " $A$ es culpable". ${ }^{29}$

Que la declaración adscriptiva: “A realizó una acción dolosa”, no sea un acto del habla, en sentido estricto, no impide que en su calidad de enunciado operativo pueda ser interpretado, a través de fórmulas pragmáticas surgidas con la pretensión de hacer más inteligible ${ }^{30}$ al acto del habla que supone afirmar en una sentencia penal que " $A$ es culpable de un delito doloso".

De esta forma, el lenguaje ordinario permite establecer un puente para una vinculación entre acciones dolosas y antijuridicidad formal. Y, al mismo tiempo, posibilita una vinculación entre la adscripción de acciones intencionales (enunciado operativo) y la culpabilidad pronunciada en la sentencia (en cuanto acto de habla performativo).

En relación con este asunto, la elucidación de los conceptos penales debería partir por una explicación certera sobre el uso distintivo de las funciones del lenguaje en conjunción con las reglas prácticas donde, precisamente, están aquellas vinculadas a la atribución del conocimiento necesario para afirmar el dolo. ${ }^{31}$ Así, la imputación subjetiva es un enunciado operativo para la determinación de niveles de relevancia en la atribución de conocimiento en las acciones realizadas por un sujeto. ${ }^{32}$ La interpretación de lo anterior desde el lenguaje supone, en conformidad a la función performativa ${ }^{33}$ de la imputación, que las palabras sean utilizadas en ella como una conjunción de reglas o modos convencionales que sirven de antecedente para atribuir significado más allá de la mera explicación causal.

\footnotetext{
28 "Operative as used by lawyer. Lawyer when talking about legal instruments will distinguish between the preambles, which recites the circumstances in which a transaction is effected, and on the other hand, the operative part- the part of it, which actually performs the legal act which it, is the purpose of the instrument to perform. So, the word "operative" is very near to what we want. I give and bequeath my watch to my brother would be an operative clause and is a performative utterance". AUSTIN, Philosophical, cit. nota n 22, p. 223. ${ }^{29}$ Un ejemplo calificado como un caso evidente de acto del habla. MACCORMICK, Neil; BANKOWSKI, Z., "Speech Acts, Legal Institutions, and Real Laws", en: MACCORMICK, N.; BIRKS, P. (Ed.) The Legal Mind: Essays for Tony Honoré, Oxford: Clarendon Press, 1986, p. 122.

${ }^{30}$ La denominada "pragmática universal" de Habermas y sus cuatro pretensiones de validez (inteligibilidad, veracidad, verdad y rectitud), tienen su origen en la teoría de los actos del habla de Austin. VIVES ANTÓN, Tomás Salvador, Fundamentos del sistema penal. Acción significativa y derechos constitucionales, $2^{\mathrm{a}}$ ed., Valencia: Tirant lo Blanch, 2011, p. 512.

${ }^{31}$ HART, H. L. A., "Problems of the Philosophy of Law", Essays in Jurisprudence and Philosophy, Clarendon Press, Oxford, 1983, p. 96. HONORÉ, A. M., "Real Laws", en: HACKER, P.M.S.; RAZ, J. (eds.), Law, Morality, and Society: Essays in Honour of H. L. A. Hart, Oxford: Clarendon Press, 1977, p. 99 y ss.

${ }^{32}$ HART, "Problems", cit. nota no 31, p. 92.

${ }^{33}$ HART, H.L.A., "Introduction", Essays in Jurisprudence and Philosophy, Oxford: Clarendon Press, 1983, p. 4.
} 
Si esto es así, entonces, las reglas relativas a la imputación subjetiva no desempeñan desde el lenguaje ningún papel orientador de acciones. En sentido fuerte, no tienen función motivadora en términos de prevención, porque son solo un conjunto de reglas prácticas para la atribución de significado a acciones vinculadas con un concreto estado de cosas. ${ }^{34}$ Tampoco, cumplirían funciones retributivas en términos de sanciones éticas por el quebrantamiento intencional de reglas; la imputación no justificaría una ética consecuencialista por la realización de acción, sino que solo sirven, en el plano meta-ético del lenguaje, para la creación de reglas prácticas para la adscripción o imputación del conocimiento necesario al dolo en el contexto institucional del proceso penal; es decir, justifican la práctica de imputar. ${ }^{35}$ En tal sentido, adscribir o imputar es una práctica realizada por un tercero quien, sobre la base de las reglas del lenguaje, atribuye conocimiento a nuestras acciones como consecuencia de la aplicación de una práctica o ritual institucionalizado. ${ }^{36}$

\section{Adscriptivismo y dogmática penal}

Hasta aquí hemos intentado abordar el problema de la atribución o imputación de conocimiento desde la siguiente premisa: dado que las personas conocen las reglas a través del lenguaje, el quebrantamiento de las prohibiciones o mandatos tiene lugar por la valoración social de la conducta. Si esto es así, entonces, la acción es un símbolo regido por normas ${ }^{37}$ cuyas proposiciones pueden desglosarse en otras a través del significado de las reglas de conducta. Es decir, la acción no es un hecho aislado, sino que es el resultado de una interpretación valorativa conforme a reglas sociales que tienen sentido según el sistema de normas penales. ${ }^{38}$ Por esta razón, una dogmática penal que asuma la teoría del lenguaje como fundamento no puede hablar de "hechos", 39 sino de acontecimientos que adquieren

\footnotetext{
${ }^{34}$ Así, HONORÉ, "Real Laws", cit. nota no 31, p. 105.

35 Esta distinción sobre las reglas prácticas, la crítica al utilitarismo y retribucionismo, la he tomado de RAWLS, John, "Two concepts of rules", The Philosophical Review, 64:1 (1955), pp. 3-32, pp. 4-19 y ss.

36 "Now by an institution I shall understand a public system of rules which defines offices and positions with their rights and duties, powers and immunities, and the like. These rules specify certain forms of action as permissible, others as forbidden; and they provide for certain penalties and defenses, and so on, when violations occur.

As examples of institutions, or more generally social practices, we may think of games and rituals, trials and parliaments, markets and systems of property. An institution may be thought of in two ways: first as an abstract object, that is, as a possible form of conduct expressed by a system of rules; and second, as the realization in the thought and conduct of certain persons at a certain time and place of the actions specified by these rules". RAWLS, John, A Theory of Justice, The Belknap Press of Harvard University Press, Massachusetts: Cambridge, 1971, p. 55. Se trata de una actividad dentro de un sistema de reglas. HONORÉ, "Real Laws", cit. nota n 31 , p. 106.

37 "La acción como un proceso simbólico regido por normas, como el significado social de la conducta, expresado lingüísticamente". VIVES ANTÓN, Fundamentos, cit. nota no 30, p. 221.

38 "Interpretaciones que, según los distintos tipos de reglas sociales, pueden darse al comportamiento humano". proceso simbólico regido por normas, como el significado social de la conducta, expresado lingüísticamente". VIVES ANTÓN, Fundamentos, cit. nota no 30, p. 221.

39 "Los hechos acaecen, las acciones tienen sentido (esto es significan); los hechos pueden ser descritos; las acciones han de ser entendidas; los hechos se explican mediante leyes físicas, químicas, biológicas, etc.; las acciones se interpretan mediante reglas gramaticales". "Es un proceso simbólico regido por normas, como el significado social de la conducta, expresado lingüísticamente”. VIVES ANTÓN, Fundamentos, cit. nota nº 30 , p. 221.
} 
sentido al ser dotados de un significado interpretado conforme a reglas gramaticales contenidas en el sistema de normas penales. ${ }^{40}$

El adscriptivismo niega el entendimiento de las acciones como fenómenos o hechos naturales y prescinde de su interpretación en sede de la voluntad como causa para la realización de un movimiento corporal o para la modificación de un estado de cosas, pasando a ser acontecimientos dotados de un significado social en relación con el lenguaje ordinario. Como afirma Hurschka ${ }^{41}$ "la acción es un acontecimiento gobernado por normas, en cuanto reglas de comportamiento apreciadas por un sujeto concreto". ${ }^{4}$

Con ello se quiere indicar que la acción no es un hecho, sino la interpretación de la aplicación de una regla del lenguaje que otorga el contenido básico para la imputación de los comportamientos humanos en una sociedad regida por normas. A partir de la comunicación se genera un consenso social sobre los comportamientos que dan forma a una convivencia normativa, lo que para Kindhäuser tiene lugar también sobre la base del lenguaje. Se trata de un enfoque "tradicional" sociológico donde "el sentido de las acciones humanas está en las interacciones comunicativas realizadas conforme a las reglas y los criterios que le otorgan significado" ${ }^{\text {. }}$.

En resumen, en contraste con la idea de una acción con contenido ontológico (como un hecho) aquí la acción es entendida como una regla de comportamiento. No se trata de una mera descripción, sino que un concepto adscriptivo, donde se interpreta el sentido que tiene ese suceso en un ámbito social concreto, conforme a sus reglas y normas; no se trata de un mero percibir un movimiento corporal o describir un acto dotado de subjetividades ligadas a la interpretación de la voluntad. ${ }^{44}$

El mérito del traslado de la filosofía del lenguaje al Derecho Penal es el abandono de las definiciones dadas por las ciencias sociales o empíricas, para pasar a conceptualizar la acción y las restantes categorías del delito, en especial, la relación de causalidad, como un proceso regido primordialmente por la atribución de comportamientos contrarios a reglas

\footnotetext{
40 "No como sustrato conductual susceptible de recibir un sentido, sino como sentido que, conforme a un sistema de normas, puede atribuirse a determinados comportamientos humanos. Se opera, así, un giro copernicano en la teoría de la acción: ya no es el sustrato de un sentido; sino, a la inversa, el sentido de un sustrato". proceso simbólico regido por normas, como el significado social de la conducta, expresado lingüísticamente". VIVES ANTÓN, Fundamentos, cit. nota no 30, p. 221.

${ }^{41}$ Para este autor el concepto de imputación o atribución que, desapareció del lenguaje del positivismo del siglo XIX, se hallaba en las escuelas de Pufendorf, Wolff y Santo Tomás. Según él, juega un papel de soporte previo para la compresión de la concepción de acción, libertad y culpabilidad. Al respecto, sostiene que su concepto de imputación es similar al de atribución (adscripción), utilizado en el referido escrito fundamental de Hart (adscription and rights). HRUSCHKA, Joachim, Strukturen der Zurechnung, Berlín: Walter de Gruyter, 1976, pp. 3 y 4 (en especial, la nota 4a añadida con posterioridad a la impresión del texto original). p. 12 y ss.

${ }^{42}$ El abandono de la idea de atribución o imputación personal habría provocado la necesidad de explicar la acción como un fenómeno puramente ontológico, cuando en realidad es un acontecimiento normativo. HRUSCHKA, Strukturen, cit. nota $\mathrm{n}^{\circ} 41$, pp. 4 y ss.

${ }^{43}$ KINDHÄUSER, Intentionale Handlung, p. 41.

${ }^{44}$ HRUSCHKA, Strukturen, cit. nota $n^{\circ} 41$, p. 13.
} 
sociales ${ }_{46}^{45}$ y que importan al Derecho en la medida que están a su vez reconocidas como normas. $^{46}$

Aquí, el concepto de seguir una regla juega, literalmente, un rol fundamental para comprender la adscripción de "comportamientos", en la medida que toma como referencia la valoración social o significado de las acciones y la forma en que los seres humanos se relacionan entre sí y se vinculan con la sociedad. ${ }^{47}$ Lo que se explica, tal como indica Winch, porque "la idea de seguir una regla es inseparable de la noción de cometer error". ${ }^{4}$

A través de las reglas del juego del lenguaje comprendemos qué es correcto y cuáles son nuestros deberes. Del mismo modo, interpretamos qué no es correcto y cuáles no son nuestros deberes y, por cierto, nosotros adscribimos a un acontecimiento o evento la categoría de contravención de un deber o le atribuimos la cualidad de ser interpretado como un error. Esta es la esencia de las reglas que sirven para la adscripción de conocimiento, en la medida que supone una valoración desde la tercera persona (nosotros) de las "conductas" realizadas por otro a partir del uso adscriptivo del lenguaje. Atribuir o imputar a un sujeto una acción o más bien la modificación de un estado de cosas es, ante todo, la constatación de la contravención a reglas sociales conocidas de comportamiento. Ello tiene lugar en la medida que "si es posible decir que alguien está siguiendo una regla, entonces, es posible preguntar si alguien está realizando o no lo correcto". 49

En el fondo las actividades humanas, entre las que se cuentan todas las necesarias para el mantenimiento de la vida en sociedad, pueden ser interpretadas o entendidas como acontecimientos dependientes del lenguaje, ${ }^{50}$ porque a través de nuestro lenguaje sabemos qué podemos o debemos hacer, conocemos qué es necesario para que algo sea entendido o no como correcto. ${ }^{51}$

Tal como lo indica Ramos Vásquez ${ }^{52}$ las reglas del juego del lenguaje son esenciales para la compresión de acciones intencionales. Aún más, solo hay acciones intencionales si suponen una contravención de reglas y solo importan al derecho en la medida que son

\footnotetext{
${ }^{45}$ Sobre este punto en la teoría del lenguaje, WINCH, Peter. The idea of a Social Science and its Relation to Philosophy, 2a. London: Routledge, 2003, pp. 10-14 y 24 y ss.

${ }^{46}$ HRUSCHKA, Strukturen, cit. nota $n^{\circ} 41$, p. 13.

${ }^{47}$ WINCH, The idea of a Social Science, cit. nota $n^{\circ} 43$, p. 24

${ }^{48}$ WINCH, The idea of a Social Science, cit. nota $n^{\circ} 43$, p. 33.

${ }^{49}$ WINCH, The idea of a Social Science, cit. nota $n^{\circ} 43$, p. 33.

${ }^{50}$ Véase, SEARLE, John, The construction of Social Reality, New York: Simons \& Schuster, 1995, pp. 59 y ss.

51 von WRIGHT, Georg, Norma y acción. Una investigación lógica, GARCÍA FERRERO, Pedro (trad.), Madrid: Edtorial Tecnos, 1970, p. 24.

52 "Es en la medida que observamos el comportamiento de los demás dentro de la complejísima multiplicidad de nuestra vida en sociedad (y, consecuentemente, de nuestros juegos del lenguaje relacionados con conceptos psicológicos), reconocemos en él las mismas características que reconocemos en nuestro propio comportamiento y que podemos tener criterios para la adscripción de estados mentales". RAMOS VÁSQUEZ, José Antonio, "Una aproximación wittgensteiniana al Derecho penal", Temas actuales de investigación en ciencias penales: memorias I Congreso Internacional de Jóvenes Investigadores en Ciencias Penales, Salamanca: Universidad de Salamanca, 2014, p. 173 (el destacado es nuestro).
} 


\section{Polít. Crim. Vol. 14, № 28 (Diciembre 2019), Art. 12, pp. 441-467 \\ [http://politcrim.com/wp-content/uploads/2019/12/Vol14N28A12.pdf]}

reconocidas a su vez como normas y alguien exige procesalmente su cumplimiento (entendido como declaración de infracción).

Es a través del lenguaje interpersonal primero e institucional después que la sociedad reconoce los comportamientos que representan, significan o son constitutivos de "actos" contrarios a reglas, porque se atribuye una contravención desde una interpretación realizada por un tercer observador sobre la base de esas reglas (lo que él conoce), con independencia de si ellas han sido o no elevadas a la categoría de normas por el Derecho.

La filosofía del lenguaje insiste en que solo es posible comprender en sede de tercera persona un comportamiento, desde que para interpretar su sentido es necesario comunicarse; sin el lenguaje no podría tener lugar un reproche a la acción misma y, por obvio que pueda resultar, lo anterior equivale a sostener que las reglas se encuentran no individual, sino que socialmente establecidas. ${ }^{53}$

En este punto, es recurrente la comparación entre la interpretación del sentido que se le atribuye a las acciones conforme a las reglas del juego ${ }^{54}$ y la valoración de las acciones (jugadas) utilizando como ejemplo el ajedrez. ${ }^{55}$ Esta analogía supone que no puedo conocer los planes (intencionalidad) de los juzgadores sino hasta que estos se manifiestan en el juego (hasta el momento en que se conocen), lo que equivale a decir que únicamente puedo conocer la intención que es interpretada conforme a las reglas o normas del juego ${ }^{56}$ : el ataque al flanco del rey solo aparece evidente una vez que se realiza la jugada que desencadena la serie de combinaciones que le dan sentido.

Por ello, en relación con el significado y los procesos internos, Wittgenstein señala (con el jugador de ajedrez como punto de referencia):

\footnotetext{
53 "Nadie capaz de establecer un estándar puramente personal de la conducta si nunca hubiera tenido alguna experiencia de la sociedad humana con sus normas socialmente establecidas", WINCH, The idea of a Social Science, cit. nota $\mathrm{n}^{\circ} 43$, p. 33.

54 "Jugar un juego es una actividad humana. Esta se desarrolla con arreglo a patrones fijos, que se pueden llamar movimientos del juego. Diremos que las reglas determinan estos movimientos o patrones - de este modo también al juego 'mismo' y la actividad de jugarlo-. Podríamos decir que, desde el punto de vista del juego mismo, las reglas determinan cuáles son los movimientos correctos, y, desde el punto de vista de la actividad de jugar, las reglas determinan cuáles son los movimientos permitidos", von WRIGHT, Norma y acción, cit. nota $\mathrm{n}^{\circ} 51$, p. 26.

55 "Cuando alguien le muestra a otro el rey del ajedrez y dice: 'Este es el rey', él no le está contando sobre el uso de la pieza - a menos que él conozca las reglas del juego hasta el último extremo: la forma de un rey. Puedes imaginar que él esta aprendido las reglas del juego sin que nunca se le haya mostrado realmente una pieza (...) Puede también imaginarse alguien que haya aprendido el juego sin haber estudiado o formulado las reglas. Él podría haber aprendido, primero, a través de la observación de juegos de tablero y, progresar bastante a otros cada vez más complejos. También se le podría dar la explicación: 'Este es el rey', si, por ejemplo, le mostrasen las piezas de ajedrez de una forma que no ha usado todavía. Esta explicación también le enseña sólo el uso de la pieza porque, como podríamos decir, ya estaba preparado el lugar donde se colocaría. O también: nosotros solo diremos que se le enseña el uso, si el lugar estaba preparado. Y, aquí es así no porque a la persona que le damos la explicación ya conozca las reglas, sino porque en otro sentido él ya domina el juego". WITTGENSTEIN, Ludwig, Philosophical Investigations, ANSCOMBE (trad.), London: A Blackwell Paperback, 1999, 31, $15^{\mathrm{e}}$.

56 “Así pues, la intención se halla referida a reglas, técnicas y prácticas, y presupone, por consiguiente, una competencia". VIVES ANTÓN, Fundamentos, cit. nota n 30, p. 243.
} 
“QQué le replicaríamos si dijera que para él saber jugar ajedrez es un proceso interno? -Que a nosotros no nos interesa nada de lo que ocurre dentro de él, cuando queremos saber si sabe jugar ajedrez-. Y, si él respondiera a esto que justamente sí nos interesa: a saber, que él sepa o no jugar ajedrez, tendríamos que hacerle notar los criterios que nos demostrarían su capacidad y, por otro lado, los criterios para los estados internos". ${ }^{57}$

Entonces, si las acciones se interpretan conforme a las reglas, para poder jugar (lo que equivale a realizar acciones), se requiere conocer las reglas del juego. ${ }^{58}$ Es más, únicamente, un tercer observador del juego de ajedrez, conocedor de sus reglas, puede valorar objetivamente, por ejemplo, si el ataque al flanco del rey era una opción "correcta", teniendo en cuenta las posibilidades que el jugador tenía al momento inmediatamente anterior al realizar el movimiento que desencadena la serie combinatoria de acciones o jugadas. Al mismo tiempo, el error que en el juego equivale a la contravención de lo correcto, puede suponer la falta de cálculo de aquella serie de combinaciones que eran posibles para lograr ganar la partida, combinaciones que, por cierto, eran también de esperable previsión por parte del jugador, teniendo en cuenta sus conocimientos sobre las reglas del juego y su experiencia.

Únicamente, el tercer observador puede valorar objetivamente si el jugador, de acuerdo con su experiencia y conocimientos, debía haber previsto que la serie combinatoria era en ese momento una opción no atendible. Es más, quien juega al ajedrez no solo conoce, sino que también debe conocer que, en general, está prohibido realizar movimientos contrarios a las reglas, entre los que resulta evidente manipular la posición de las piezas sobre el tablero o adulterar la papeleta de anotaciones o el reloj. En fin, se trata de prohibiciones que son evidentes porque su realización impide en términos absolutos el desarrollo del juego que, como modo de comunicación, es una regla básica de reconocimiento recíproco. ${ }^{59}$

También, el jugador conoce que tiene ciertas obligaciones como la de permanecer sentado durante el juego o la de advertir al árbitro sobre cualquier comportamiento que pueda intervenir en el también "correcto" desarrollo del torneo de ajedrez. Aquello, "lo sabe" o "conoce" por la experiencia que implica el jugar con otros, incluso sin haber leído el reglamento ni estar advertido o intimidado por las sanciones específicas que este contiene. De ahí, entonces, que la atribución de la contravención de lo correcto se encuentre en la

\footnotetext{
${ }^{57}$ WITTGENSTEIN, Philosophical Investigations, cit. nota 55, II, vi, $181^{\mathrm{e}}$.

58 "Seguir una regla, hacer un informe, dar una orden, jugar una partida de ajedrez son costumbres (usos, instituciones). Entender una oración significa entender un lenguaje. Entender un lenguaje significa dominar una técnica”. WITTGENSTEIN, Philosophical Investigations, cit. nota 55, I, 199, 81e. Y, por eso, la acción es un problema de lenguaje, un proceso simbólico regido por normas, donde el significado social de la conducta, se expresado lingüísticamente. VIVES ANTÓN, Fundamentos, cit. nota no 30, p. 227.

${ }^{59}$ El principio del discurso de Habermas permite analizar o examinar el contenido de legitimidad de las normas de acción, en la medida que únicamente tienen tal carácter las aceptadas por los partícipes como un discurso racional. HABERMAS, Jürgen, Facticidad y validez. Sobre el Derecho y el Estado democrático de Derecho en términos de teoría del discurso, JIMÉNEZ REDONDO (trad.), Madrid: Trotta, 2005, pp. 187190.
} 
pragmática de la acción misma, ${ }^{60}$ con independencia de la función trascendente que la sanción pueda cumplir a modo de advertencia.

\section{La relación entre adscripción, significado y conocimiento}

Geach ofrece un argumento en contra de las tesis adscriptivistas de las acciones. ${ }^{61}$ Señala que, si bien es posible compartir las objeciones que se formulan a la aproximación tradicional, según la cual un acto es y debe ser explicado por una relación causal o teleológica, no sería del todo factible, sin embargo, negar en términos absolutos (lo que sería el error del adscriptivismo), la importancia que tal aproximación le otorga a la voluntariedad e intencionalidad de las acciones, en especial para la construcción posterior de la relación de causalidad entre una conducta y un estado de cosas (resultado). Para este autor $^{62}$ el problema de adscribir un comportamiento y no describirlo como un acto voluntario, conlleva una inaceptable declaración "precipitada" de responsabilidad moral. Esto ocurre, porque adscribir supone que $B$ está de acuerdo con la valoración que $C$ realiza del comportamiento $(p)$ de $A$. Sostener que $B$ asume una posición moral en relación con el acto realizado por $A$, le parece a Geach una postura inadmisible, porque en el lenguaje ordinario, en el sentido general del uso de las palabras, describir la acción realizada por $A$, no se supone asumir una posición moral o cuasimoral, ni relación legal en términos de atribuir o imputar preliminarmente responsabilidad; simplemente, se dice que $A$ realizó una acción determinada, sin usar lenguaje de imputación alguno. ${ }^{63}$ Lo que Geach califica como un "error grave" es pretender "la utilización de un término $(p)$ como la representación de alguna otra naturaleza que la descripción de la cosa". De este modo, en la tesis de la adscripción "lo que se ignora con regularidad es la diferencia entre llamar a una cosa $(p)$ y predicar de $(p)$ una cosa". 64

Por ello, el afirmar que algo ha ocurrido no quiere decir que se pueda predicar que ese algo sea verdadero o falso. En consecuencia, si $C$ puede decir junto con $B$ que el comportamiento de $A$ es acontecimiento interpretable en relación con la producción de un

\footnotetext{
60 “Según la concepción pragmático-formal, la estructura interna racional de la acción orientada al entendimiento se refleja en las suposiciones que los actores deben adoptar cuando entran sin reservas en esa práctica. El carácter necesario de ese 'deber' tiene que entenderse más bien en el sentido de Wittgenstein que en el de Kant, es decir, no en el sentido trascendental de las condiciones universales, necesarias e inteligibles (y sin orígenes), de la experiencia posible, sino en el sentido gramatical de la `inevitabilidad’ que resulta de los nexos conceptuales internos de un sistema de comportamiento guiado por reglas que hemos socializado y que, en cualquier caso, para nosotros es irrevisable". HABERMAS, Jürgen, "Acción comunicativa y razón sin trascendencia”, HABERMAS, J., Entre Naturalismo y Religión, Barcelona: Paidós, 2006, p. 34.

${ }^{61}$ GEACH, P. T. “Ascriptivism”, The Philosophical Review 69:2 (1960), pp. 221-225.

${ }^{62}$ GEACH, “Ascriptivism”, cit. nota 51, p. 221.

${ }^{63}$ Así, una valoración puramente objetiva o externa de una acción prescinde de la circunstancia de que no es otra cosa que la interpretación de la voluntariedad de las acciones, su valoración o prueba, lo que determina la legitimidad del reproche moral. En efecto, es el rescate del silogismo práctico, lo que introduce desde Anscombe, un giro radical en la moderna filosofía del lenguaje. Al respecto, sobre la relación entre intencionalidad y acción, GONZÁLEZ LAGIER, Daniel, Acción y norma en G. H. von Wright, Madrid: Centro de Estudios Constitucionales, 1995, p. 149 y ss. HIERRO S. PESCADOR, José. "En torno a la intencionalidad", Revista de Filosofía, 14 (1994), pp. 29-44, pp. 33 y ss.

${ }^{64}$ GEACH, P. T. “Ascriptivism”, cit. nota $\mathrm{n}^{\circ}$ 51, p. 223.
} 
determinado estado de cosas, ello no quiere significar que se pueda predicar en términos de veracidad que esa acción sea intencional. $^{65}$

Para superar tal crítica, es necesario aceptar que la posibilidad de adscribir a una persona la realización de una acción dolosa, supone obligatoriamente, en primer lugar, que la acción pueda ser explicada a través de la atribución de un significado, entendido como el resultado de la racionalización o del conocimiento de las acciones: es interpretar una decisión personal de dirección de comportamiento, mediante un silogismo práctico construido en vinculación con normas jurídicas $\mathrm{y}$, en segundo lugar, asumir que la explicación del significado supone, en realidad, que nosotros podamos atribuirle, en el contexto en que ha tenido lugar (ex ante), el quebrantamiento de una norma. Y, por cierto, no cualquier tipo de quebrantamiento, sino que uno que signifique, en el contexto en que ha tenido lugar, algo diferente a una mera inadvertencia o un error; es la imputación de conocimiento al autor en un contexto institucional preciso que no es otro que el proceso penal. ${ }^{66}$

La adscripción o imputación del significado de una conducta se realiza en el Derecho, a través de un proceso institucional que implica la formulación del enunciado performativo de responsabilidad, al modo: “ $A$ mató dolosamente a $B$ ”, sin que esa afirmación, implique, como se ha apuntado, la formulación de un reproche moral (culpabilidad, en sentido estricto). En el contexto institucional (el proceso) opera sobre la base de un conjunto de reglas prácticas de atribución institucional de significado a título de conocimiento (esto es el dolo) que conllevan no solo la creación de una regla para el caso simple (dolo directo/absicht), sino también supuestos en que se imputa el conocimiento de la relación de causalidad, la decisión de ignorar conscientemente y el actuar con previsión de las consecuencias. ${ }^{67}$

Si bien podría resultar dudoso el formular enunciados de acción en términos de atribución de responsabilidad bajo la pretensión de equiparar la descripción " $A$ mató a $B$ ” con la adscripción " $A$ realizó un homicidio intencional", la tesis es correcta, en la medida que, supone adherir a una postura no derrotada de filosofía del lenguaje según la cual "el uso del lenguaje, o la fuerza de las oraciones, o el tipo de acto lingüístico que se realiza al decir algo determina el significado de las expresiones empleadas". 68

\footnotetext{
65 Sobre este punto, esencial, es la reciente aportación de SEARLE, John, Rationality in Action, Massachusetts: A Bradford Book: The MIT Press, 2001, pp. 33 y ss.

${ }^{66}$ Especialmente, GONZÁLEZ LAGIER, Acción y norma, cit. nota no 63, p. 150 y ss. También, SEARLE, Rationality, cit. nota $\mathrm{n}^{\mathrm{o}} 65$, pp. 35 y ss.

${ }^{67}$ Se trata de lo que Peter Hacker denomina la tercera posición táctica (elaborada por Searle, Davidson y Geach), que consiste en adscribir otorgando significado intencional a acciones en contextos de lenguaje, también, por cierto, institucionales. Es una opción, que supone la no negación de la intencionalidad y de lo interno, en la medida que lo interno, puede ser interpretado desde la tercera persona, como la manifestación de una acción racionalizada por la intención. La citada tercera opción táctica, aparece referida por Hacker del siguiente modo: "A third tactical option (also present in the Tractatus, and pursued in a different form bi Grice and Searle) ascribes the intentionality of the signs of speech to intentions of the speakers, to his meaning what he does by the Word he utters, it being of the nature of intention and of meaning something to be intentional", HACKER, P. M. S. "Davidson on Intentionality and Externalism”, Philosophy 73 (1998), 539-552, p. 541.

${ }^{68}$ NINO, Carlos, Introducción a la filosofía de la acción humana, Buenos Aires: Eudeba, 1987, p. 18.
} 
Y, entonces, la objeción que realizara Pitcher ${ }^{69}$ en el sentido de que la tesis de Hart puede ser aplicable a los casos en que se trata de imputar o atribuir responsabilidad en contextos de acciones penales, pero no así en la generalidad de los casos, resulta acertada para los fines de este trabajo. Por ello, conforme se ha indicado, una tesis adscriptiva conlleva asumir que las condiciones que derrotan el enunciado de conducta al modo " $A$ mató a $B$ " son siempre condiciones negativas y abiertas. ${ }^{70}$

Así, las acciones serían interpretables conforme a reglas y, por ende, el predicar que " $A$ mató a $B$ " es una afirmación de contravención de normas de conducta que prima facie habilita para el análisis de decisión (en el sentido indicado supra), sobre la concurrencia de una excusa o defensa. ${ }^{71}$ Únicamente, se puede imputar significado a una conducta si ella es puesta en relación o con referencia a reglas, por eso, solo sabemos si alguien juega un juego si sigue las reglas y nosotros conocemos o sabemos cuáles son las reglas del juego; es por esta razón también que, el significado de una acción penal surge de la sumisión a reglas, dentro de las cuales se encuentran los imperativos y, por ello, el concepto de acción solo resulta interpretable conforme a su predicado normativo. ${ }^{72} \mathrm{El}$ mérito de las tesis adscriptivas consiste en otorgar contenido a la atribución de significado de las acciones más allá de la mera descripción de un movimiento corporal. ${ }^{73}$

\footnotetext{
${ }^{69}$ Según Pitcher la tesis original del adscriptivismo (sin referencias al concepto de significado) contenía una incorrección en el lenguaje, desde el momento en que solo sería posible responsabilizar y adscribir - en puro sentido negativo - una conducta si se puede entender que quien ha realizado la acción (en sentido descriptivo), tenía además un deber o una obligación de abstención o prevención de ciertas consecuencias, resultados o estados de cosas. A continuación, sostiene que de alguna forma habría que pedir una explicación para no atribuir culpabilidad de un modo puramente mecánico. Por esta razón, lleva razón en el sentido que el concepto de responsabilidad que utiliza Hart es extremadamente ambiguo, porque incluso entendiéndolo en un sentido limitado no sería aceptable; es más, sería errado entender que es posible aceptar que un enunciado de acción puede implicar adscripción de responsabilidad en sí mismo (como ocurre con el testigo que observa un homicidio y le señala a la policía el autor, utilizando un lenguaje aseverativo, diciendo: "él lo hizo"); en consecuencia, lo único que puede implicar adscripción, en sentido de responsabilidad, es la posibilidad de imputarle a un sujeto la realización de una acción entendida como la prohibición o el mandato de evitación de producción de un estado cosas. La crítica sería que no es posible entender que la formulación de una expresión del lenguaje en relación con una acción puede significar atribución de responsabilidad, porque más bien la adscripción de responsabilidad debería estar fundamentada en la realización de una prohibición o la abstención de ejecución de una acción en la medida que produce un estado de cosas antijurídico. En consecuencia, según Pitcher cuando Hart dice que el formular una expresión del tipo "Smith le golpeó", equivale a adscribir responsabilidad a Smith por su acción, tiene en realidad un valor relativo y excepcional, en la medida en que se utilice en la oración un verbo intencional de acción, pero no pasaría lo mismo con el uso de formas verbales neutras, entre las que estaría, por cierto, " $A$ mató a $B$ ". PITCHER. G. "Hart on Action and Responsibility", The Philosophical Review 69, 2 (1960), pp. 226 - 235, passim. También, PUTNAM, Hilary, Representación y realidad. Un balance crítico del funcionalismo, Barcelona: Gedisa, 2014, pp. 23, 31 y ss.

${ }^{70}$ NINO, Introducción, cit. nota n ${ }^{\circ} 68$, p. 19.

${ }^{71}$ En tal sentido, aquí operaría una forma característica de intuicionismo ético, desde que la afirmación de que "A mató a $B$ " merece el análisis sobre si de ella puede predicarse algo "bueno" o "malo".

72 MARTÍNEZ GARAY, Lucía, Proyecto docente e investigador (inédito), Valencia: Universidad de Valencia, 2004, pp. 150-151.

${ }^{73}$ En efecto, las tesis de Davidson, Searle y Grice suponen una superación de la versión original en la medida que asumen una interpretación del concepto de significado, a partir de la referencia que Wittgenstein realizara sobre la intención. "247. Solo tú puedes saber si tuviste la intención. Se le podría decir esto a alguien al explicarle el significado de la palabra "intención”. Pues quiere decir entonces: así es como la usamos.
} 
Con todo, la tesis no ha estado exenta de críticas, aunque Feinberg señala que no hay acuerdo sobre qué errores son, específicamente, aquellos en los que habría incurrido la tesis adscriptiva de las acciones, en la medida que al menos existiría un tipo de acción descriptiva que prima facie ofrece un argumento a favor de esta tesis ${ }^{74}$. Sin embargo, la validez del argumento está condicionado a que se asuma la posibilidad de valoración de los sucesos o acontecimientos ejecutados por otro, desde la perspectiva de la tercera persona, renunciado a la pretensión de averiguación de procesos internos. Al respecto, Feinberg ofrece el ejemplo de los jugadores de cartas:

"Un jugador observa a los otros hacer trampa, los descubre y pronuncia el enunciado adscriptivo de responsabilidad al modo: ¡usted hace trampa! y, eso constituye en su opinión hacer algo más que la mera descripción de los movimientos corporales' $\mathrm{y}$, por ende, resulta plausible interpretar expresiones de este tipo como afirmación de que una persona es merecedora de censura o castigo por lo que ha hecho",75.

Lo mismo ocurre en los supuestos en que conforme al lenguaje ordinario, se le atribuye a una persona la realización de un desempeño insatisfactorio o defectuoso, al modo "¡te has portado mal!", lo que no solo tiene lugar si se utiliza un verbo condenatorio, sino también en el evento que se le impute a una persona la comisión de un error de cálculo ("¡te has equivocado!"). Aunque no en todos los casos, sino que solamente en aquellos en los que de alguna forma prima facie puede afirmarse o predicarse responsabilidad en un sentido fuerte ("has obrado mal porque no cumpliste con lo que debías y podías hacer", lo que supone volver al citado silogismo práctico); esto es, porque conforme a la evidencia argumentativa que existe al respecto podemos decir que se ha contravenido una regla o norma de conducta. Y, solo en tales supuestos, el enunciado asdcriptivo de responsabilidad es derrotable por la presencia de un permiso fuerte o débil. ${ }^{76}$

En este lugar, intentaré ofrecer un argumento para la superación de las críticas que, desde la filosofía de la acción, han sido objeto las concepciones adscriptivas. De todas ellas, a mi juicio la más sólida y de difícil refutación es la formulada por González Lagier ${ }^{77}$ para quien el adscriptivismo lleva al extremo la analogía entre enunciados lingüísticos y el significado de nuestras acciones, sin especificar, primero, qué entiende por ambas cuestiones y, segundo, sin indicar cuál sería el límite entre ambos. En este plano, se dice que la citada ambiguiedad consiste en que no expresa con claridad cuál es el concepto de significado que sigue o adopta para construir la imputación en sede de la tercera persona.

(Y "saber" quiere decir aquí que la expresión de incertidumbre carece de sentido)". WITTGENSTEIN, Philosophical Investigations, cit. nota 55, I, 89e, 247.

${ }_{75}^{74}$ FEINBERG, “Action", cit. nota ${ }^{\circ} 16$, pp. 119-120.

${ }^{75}$ FEINBERG, "Action", cit. nota n ${ }^{\circ}$ 16, p. 120.

${ }^{76}$ FEINBERG, “Action”, cit. nota n ${ }^{\circ}$ 16, p. 122.

77 GONZÁLEZ LAGIER, Daniel, Las Paradojas de la Acción, 2a ed., Madrid: Marcial Pons, 2013, pp. 71-72 y 113 y ss. La citada búsqueda del concepto de significado aparece, en relación con las tesis adscriptivas, por ejemplo, BUSATO, Paulo, "Dolo y significado", Revista General de Derecho Penal, 6 (2006), pp. 16 y ss. 


\section{Polít. Crim. Vol. 14, № 28 (Diciembre 2019), Art. 12, pp. 441-467 \\ [http://politcrim.com/wp-content/uploads/2019/12/Vol14N28A12.pdf]}

La denominada por Hacker como la tercera opción táctica ${ }^{78}$ ofrece la posibilidad de superación de esta crítica y una reconstrucción del concepto de significado de las acciones en el contexto del Derecho penal. Y, en relación con los enunciados lingüísticos, la construcción de la adscripción desde el lenguaje puede recurrir a los criterios de valoración de la intencionalidad de las acciones, siguiendo en este punto las tesis de Searle y Davidson. Al mismo tiempo, junto con seguir la citada tercera opción táctica, el argumento de Grice ${ }^{79}$ para la distinción de significado atemporal y ocasional es, a mi juicio, esencial.

Sobre la base que un enunciado preposicional puede desglosarse hasta llegar a los objetos y los hechos atómicos, expresados en fórmulas, Grice distingue entre el significado atemporal de un enunciado preposicional y el significado ocasional. Así, por ejemplo, decir $A$ disparó a $B$ cinco tiros con un arma de fuego a dos metros de distancia, podría desglosarse del modo que sigue:

a) Puede decirse que es verdadero que disparar consiste (aproximadamente) en despedir la carga de un arma, que cinco y dos son números que otorgan medidas cuantitativas, tal como lo hace el metro como unidad de medida. Se trata de expresiones no lingüísticas de un enunciado preposicional de naturaleza atemporal (significado atemporal).

b) Ahora bien, el proferir un enunciado del tipo $A$ disparó intencionalmente a $B$, es en términos de lenguaje ordinario especificar un significado ocasional.

c) En este tipo de uso del lenguaje adscriptivo puede reconocerse la intención de A, aunque $A$ no dijese ninguna palabra.

d) Para ello es necesario que en la interpretación de la acción $C$ (la tercera persona) pueda decir o predicar que $A$ tenía la intención que se reconociera su propósito de matar a $B$ (significado ocasional).

Para la comprensión de la interpretación de intenciones conforme a las circunstancias, puede ofrecerse como ejemplo el caso del hombre que juega bridge "contra" su jefe. Este caso se originó en el contexto de la discusión entre cómo distinguir o averiguar la intención en relación con los actos del habla (Strawson): ${ }^{80}$

"Un hombre juega bridge contra su jefe. Quiere agradarle y, por esta razón quiere que él gane. Es consecuencia, quiere que su jefe sepa que él quiere que gane (a su jefe le gusta este tipo de humildad). Sin embargo, él no quiere hacer nada escandaloso, como decirle a su jefe una palabra o, en efecto, contarle a través de una alguna acción que importe una señal, por miedo a que su jefe pueda sentirse ofendido por su tosquedad. Entonces, él pone en marcha el siguiente plan: cuando tenga una buena mano, sonreirá de un modo certero; la

\footnotetext{
${ }^{78}$ HACKER, P. M. S. “Davidson on Intentionality and Externalism”, Philosophy, 73 (1998), pp. 539-552, pp. 541 y ss.

${ }^{79}$ GRICE, H. P. "Meaning”, The Philosophical Review, 66; 3 (1957), pp. 377-388, passim.|

${ }^{80}$ STRAWSON. P. F. "Intention and Convention in Speech Acts", The Philosophy of Language, ed. J. R. Searle, Oxford: Oxford University Press, 1977, pp. 23 y ss.
} 
sonrisa será muy evidente, pero no como una sonrisa espontánea de placer. Intentará que su jefe detecte la diferencia, del modo siguiente: Eso no era una forma genuina de regular una sonrisa, pero sí la simulación de una"81.

Según lo indicado, este ejemplo fue elaborado en el marco de una discusión que pretendía explicar cómo, desde el punto de vista de la teoría del lenguaje, podía comprenderse la intencionalidad en el tipo de acto-básico analítico: "el movimiento corporal acompañado de una intención" 82 que junto con ser ilocutorio no es performativo, es decir, carece del poder de conferir o crear una regla y, además, es "informal", en la medida que se trata de propuestas indicativas a otras personas que solo pueden ser precisadas conforme al lenguaje, si se ponen en referencia con el efecto interlocutorio que producen, esto es, como decíamos al principio, con la valoración de una intencionalidad (lo interno).

Pese a que es evidente que este argumento queda condicionado por la circunstancia que Grice en realidad buscaba dar un contenido analítico a un tipo específico de actos del habla racionales, donde el hablante emite palabras con un sentido lógico sirve, sin embargo, para construir una explicación en favor de la noción de significado convencional. Al respecto:

"Una distinción en lo que ha dicho el hablante (con seguridad ha favorecido y, probablemente con algún acuerdo artificial, el sentido de lo que ‘él dijo'), y qué es lo que habría implicado (dado a entender, indicado o sugerido, etc.), teniendo en consideración que lo que él ha dado a entender puede ser convencionalmente comprendido (sugerido en virtud del significado de alguna palabra o frase que ha utilizado) o no convencionalmente comprendido, (sugerido a través de la en virtualidad del significado o frase que ha utilizado)". ${ }^{83}$

De este modo, el significado de las acciones no puede renunciar a la perspectiva de quien realiza la acción o "el hablante" (para ponerlo en la terminología de la discusión Grice Davison) y, por ende, no depende solo de quien observa la acción o "el oyente". Y, al mismo tiempo, se debe asumir que es factible probar -en términos de interpretación- que hacer o comunicar algo es una forma a través de la cual quien emite o profiere unas palabras o realiza una acción porque quiere (en un sentido fuerte) que su intención (como algo interno) sea reconocida por otro, en términos de racionalidad ${ }^{84}$.

El ejemplo del jugador de bridge puede ser interpretado también como un acto ilocutorio en contravención a una regla del juego, es decir, que quien observa (el jefe), puede atribuirle el significado de una acción que quebranta intencionalmente la prohibición de realizar trampa, porque el empleado no se comporta de un modo correcto. Pero, para que podamos entender que esta acción significa hacer trampa, no solo el destinatario (el jefe) debe poder interpretar ese acto como un quebrantamiento de una regla del juego, sino que además

\footnotetext{
${ }^{81}$ GRICE, H. P. "Utterer's meaning and intentions", The Philosophical Review, 78; 2 (1969), p. 154.

${ }^{82}$ MACCORMICK; BANKOWSKI, "Speech Acts", cit. nota no 29, p. 122.

83 GRICE, H. P. "Utterer's meaning, sentence- meaning, and word-meaning”, en: SEARLE, J.R., The Philosophy of Language, e Oxford: Oxford University Press, 1977, pp. 54 y ss.

${ }^{84}$ Entiende que la noción de intencionalidad ("intensionality") puede dar significado a las acciones en contraste con su extensión, es decir, el concepto de acción en toda su extensión solo cobra sentido si se le pone en referencia con "intensionality". GRICE, "Utterer's meaning”, cit. nota n 83, p. 69.
} 


\section{Polít. Crim. Vol. 14, № 28 (Diciembre 2019), Art. 12, pp. 441-467 \\ [http://politcrim.com/wp-content/uploads/2019/12/Vol14N28A12.pdf]}

quienes observan o participan del juego (un tercero u otro jugador), deben atribuirle el sentido de un comportamiento que escapa o rehúye una regla del juego.

Este ejemplo se introduce, precisamente, en un contexto donde se discutía la posibilidad de explicar el contenido de las acciones sobre la base de una intencionalidad del agente expresada en una "razón que racionaliza la acción", 85 lo que permitiría ofrecer una compresión sobre las motivaciones que habría tenido el autor para obrar de un modo u otro, su particular vinculación con las normas y una valoración subjetivada del juicio de atribución de responsabilidad, desde que se asume que es posible explicar esa "racionalización" como un proceso interno.

Asumiendo que no sería del todo descartable la idea de que "la razón racionaliza la acción", Davidson $^{86}$ entiende que no es lo mismo la acción como evento o estado de cosas que las razones que ha tenido el sujeto para ejecutar la acción.

Es decir, que sería equivocado pretender equiparar el acto de encender la luz con el compromiso intencional ligado a la acción misma de encender la luz ${ }^{87}$ (la ausencia de referencia al significado ocasional genera una de las citadas críticas a la concepción adscriptiva), en la medida que se trata de oraciones lógicamente independientes: el estado de cosas que supone que la luz esté encendida únicamente es explicable como un acontecimiento producto de una intención que racionaliza la acción.

De este punto de vista, resulta innegable que el explicar, interpretar y valorar una acción es siempre un proceso que supone reescribir la acción desde el acontecimiento o evento explicable como una consecuencia de la intencionalidad de un sujeto, acontecimiento que debería colocarse en un contexto social valorativo más amplio, porque de lo que se trata es de comprender "el propósito de la acción en su contexto de reglas, costumbres, convicciones y expectativas". 88

De este modo, un enfoque analítico como el expuesto, conlleva una vinculación entre la experiencia y realidad. Esto supone atribuirle un sentido a la acción en referencia con las reglas y normas jurídicas, entendidas como imperativos de conducta. Por ende, las definiciones legales o dogmáticas que se utilizan para interpretar el ámbito de aplicación e incidencia de una norma no tienen sentido por sí solas, sino que lo cobran en referencia con el lenguaje, ya que "en el contexto del lenguaje una oración y, por tanto, una palabra tiene significado". 89 Por ello, una acción significa interpretar un estado de cosas conforme a

\footnotetext{
${ }^{85}$ DAVIDSON, Donald, “Actions, Reason, and Causes", Essays on Actions and Events, 2 ${ }^{\mathrm{a}}$ ed. Oxford: Oxford University Press, 2001, p. 3.

${ }^{86}$ Este ejemplo supone que puede resultar engañoso el pretender establecer un paralelo entre "yo encendí la luz" y "quise encenderla", porque no son lo mismo, el primero, requiere que pueda constarse el suceso como acontecimiento real, mientras que, el segundo, precisa de que sea verdad de que quise prender la luz. DAVIDSON, “Actions", cit. nota 83, p. 9.

${ }^{87}$ DAVIDSON, “Actions", cit. nota 83, p. 9.

${ }^{88}$ DAVIDSON, "Actions", cit. nota 83, p. 10.

89 DAVIDSON, D. "Truth and Meaning", Synthese 17; 3, Language in Use Including Wittgenstein's Comments on Frazer and Symposium on Mood and Language-Games (1967), p. 304.
} 
reglas, atribuyéndole un sentido socialmente inequívoco por parte de quien o quienes reconstruyen el acontecimiento. ${ }^{90}$

\section{Conclusión: a modo de síntesis}

Aunque durante la exposición de los capítulos anteriores hemos ido introduciendo de modo paulatino nuestras consideraciones sobre el dolo, corresponde aquí, a modo de resumen, exponer nuestra posición al respecto. Según ha podido observar, adherimos a una tesis que considera que la "decisión intencional" de una persona contra las normas de prohibición de causación de resultados o que suponen el deber de abstención de realización de un comportamiento, es un acontecimiento interpretable en un contexto institucional, conforme a un significado que nosotros (un tercero) construimos en función de la relación entre el lenguaje, las reglas sociales y las normas jurídicas. Ese significado está dado por la valoración en sede de tercera persona, por una adscripción de un concreto nivel de conocimiento que, en términos de prueba del dolo, se traduce en una valoración objetivable del significado intencional de la acción. ${ }^{91}$

En otras palabras, el conocimiento es una relación de atribución de significado conforme a normas. Se trata de la adscripción de acciones en una modalidad especialmente intensa de compromiso personal con la realización de contrarias a las prohibiciones o mandatos conminados con pena. ${ }^{92}$ Esto en contraste con los supuestos en que puede atribuirse a una persona la realización de una acción que, en el lenguaje ordinario, es entendida como una inadvertencia o error de cálculo acerca de los peligros que una persona racional y prudente, situada en la posición del autor, tenía el deber de advertir, lo que supone excluir el conocimiento necesario para afirmar el dolo (imprudencia).

\footnotetext{
${ }^{90}$ Se trata entonces de una teoría puramente empírica del significado de las acciones penales que tendría por finalidad el dar cuenta de cómo es posible construir la imputación en vinculación con el lenguaje ordinario. En otras palabras, "una teoría del significado (en un sentido ligeramente perverso) es una teoría empírica y su ambición es dar cuenta del funcionamiento del lenguaje natural. Como cualquier teoría, puede ser puesta a prueba a través de la comparación de algunas de sus consecuencias con los hechos", DAVIDSON, "Truth and Meaning", cit. nota no 89, p. 311.

${ }^{91}$ En este mismo sentido, se ha dicho que "el dolo es una realidad normativa, que no existe en el mundo de la naturaleza; su existencia aparece con el proceso jurídico de enjuiciamiento de un hecho, y se construye jurídicamente a partir de los fines del Derecho penal" y, "para asignar al hecho doloso una mayor pena que al hecho imprudente. El hecho doloso es un hecho institucional en el sentido que Searle le da a la expresión, de modo que las reglas conforme a las cuales se decide jurídicamente que un hecho es dolo son reglas constitutivas". Se trata de sustituir "lo interno subjetivo" por "indicios objetivos", PÉREZ MANZANO, Mercedes, "Dificultad de la prueba de lo psicológico y naturaleza normativa del dolo", en: GARCÍA VALDÉS, et al. (Coords.), Estudios Penales en Homenaje a Enrique Gimbernat, t. I, Madrid: Editorial Edisofer, 2008, pp. 1453-1486, p. 1462.

${ }^{92}$ En este punto, la tesis que aquí se sostiene coincide con la posición de Carbonell Mateu quien afirma que de lo que se trata es de "afirmar un cierto grado de voluntad: la intención, que supone un compromiso de actuar. $\mathrm{Si}$, por otra parte, la acción es significado, el dolo significa compromiso con ese significado. El dolo, pues, supone intención, y puede ser definido como el compromiso del agente con el significado de su actor. Implica, por tanto, una absoluta coincidencia entre el aspecto objetivo y lo que este implica de una parte y el compromiso con esa significación lesiva de otra", CARBONELL MATEU, Juan Carlos, "Sobre tipicidad e imputación: reflexiones básicas en torno a la imputación del dolo y la imprudencia", en: DE TOLEDO Y UBIETO, E.; GURDIEL, M.; CORTÉS, E. (Coord.) Estudios penales en recuerdo del profesor Ruiz Antón, Valencia: Tirant lo Blanch, 2004, pp. 139-156, p. 150.
} 


\section{Polít. Crim. Vol. 14, № 28 (Diciembre 2019), Art. 12, pp. 441-467 \\ [http://politcrim.com/wp-content/uploads/2019/12/Vol14N28A12.pdf]}

En el curso de este trabajo, hemos dado cuenta de los fundamentos filosóficos en los que se sustenta esta tesis. Por el momento, puede aquí indicarse lo siguiente, a modo de resumen, acerca de los aspectos que han sido objeto de nuestra discusión:

a) Un Derecho Penal racionalmente fundado debería renunciar a la pretensión de construir una naturaleza de lo mental y una explicación de su relación con las acciones humanas, exclusivamente, desde la perspectiva de la primera persona ${ }^{93}$.

b) Lo anterior, porque constituiría un error categorial enunciado peyorativamente con la metáfora del "fantasma dentro de la máquina", pretender afirmar que: (i) es posible conocer de alguna forma la voluntad de las personas. Si esto es así, todo lo que se diga en relación con ello, no es más que conjeturas. Al mismo tiempo, según la misma posición teórica (ii) toda pretensión de explicación lógico-racional de la vinculación entre la voluntad humana, entendida como causa de las acciones y la realización o modificación de un estado de cosas, está basada en una conexión, por así decirlo "misteriosa" o "incomprobable" 94 .

c) Que el lenguaje privado no pueda conocerse, no quiere decir que no pueda interpretarse ${ }^{95}$ o valorarse normativamente de acuerdo con el significado que nosotros le atribuimos a un acontecimiento o evento en cuanto estado de cosas; es la valoración del significado que en términos objetivos puede dársele a un comportamiento en un concreto ámbito socialcomunicativo 96 .

d) Esto supone necesariamente asumir una perspectiva de tercera persona ${ }^{97}$ en la valoración de los acontecimientos externos con relevancia penal, esto es, un modo de adscribir un comportamiento sobre la base de un contexto institucional, contextual y significativo ${ }^{98}$. Así, más allá de si el dolo no es un querer, sucede que ese querer no puede ser acreditado en el proceso penal (solo podemos interpretar lo que conocemos, pero no averiguar la intención $)^{99} \mathrm{y}$, por ende: el dolo como conocimiento es una realidad normativa construida sobre la base de lo que nosotros interpretamos conforme a determinadas reglas o normas.

\footnotetext{
${ }^{93}$ Aunque las modernas teorías del lenguaje han decantado en una perspectiva que supone el reconocimiento de la voluntad de las acciones, entendida como una intencionalidad valorable en sede de tercera persona, en oposición a la idea original que negaba todo valor sobre la base de la distinción entre lo interno y lo externo. Acerca de la negación del elemento "volitivo" y, en especial, la discusión en torno a este en Alemania, KINDHAÜSER, Urs, "Der Vorsatz als Zurechnungskriterium”, ZStW, 96 (1984), pp. 96 y ss.

${ }_{95}^{94}$ RYLE, Gilbert, The Concept of Mind, London: Hutchinson`s University Library, 1951, pp. 11-23.

${ }^{95} \mathrm{Al}$ respecto, RAMOS VÁSQUEZ, José Antonio, Concepción significativa de la acción y teoría del delito, Valencia: Tirant lo Blanch, 2008, pp. 444 y ss. En relación con los procesos de "vida psíquica interna", BUSATO, Paulo, Derecho penal y acción significativa. Un análisis de la función negativa del concepto de acción en Derecho Penal, Valencia: Tirant lo Blanch, 2007, pp. 238 y ss.

${ }^{96}$ Esta idea en DAVIDSON, “Actions", cit. nota 83, p. 10.

${ }^{97}$ En relación con la diferencia de aproximación a la filosofía de la mente en primera y tercera persona. MOYA, Carlos, J. Filosofía de la Mente, Valencia: PUV, 2004, pp. 43 y ss.

${ }^{98}$ Véase, WITTGENSTEIN, Ludwig, Cuadernos de Azul y Marrón, GUILLÉN, Gracia (trad.), Madrid: Tecnos, 1976, pp. 62 y ss.

${ }^{99}$ Fundamental, en especial, porque intenta precisamente esta reconstrucción desde las modernas teorías del lenguaje que no niegan valor a la posibilidad de interpretar lo mental, apartándose de la idea radical que suponía en un principio interpretar a Wittgenstein hasta el extremo de caer en un conductismo lógico, al modo de Ryle. PÉREZ MANZANO, “dificultad de la prueba”, cit. nota no 91, pp. 1459-1461 y 1476 y ss.
} 


\section{Bibliografía}

ANSCOMBE, G. E. M. "Intention", Proceedings of the Aristotelian Society, New Series, Vol. 57 (1956- 1957), pp. 321-332.

ARISTÓTELES, Ética Nicomáquea, PALLÍ BONET (trad.), Madrid: Gredos, 2011.

AUSTIN, J. L. How to do things with words, The William James Lectures delivered at Harvard University in 1955, Oxford: Clarendon Press, 1962.

AUSTIN, J. L. Philosophical Papers, Oxford: Clarendon Press, 1961.

AUSTIN, John, Lectures on Jurisprudence. The Philosophy of Positive Law, New York: Henry Holt and Company, 1875.

BUSATO, Paulo, “Dolo y significado", Revista General de Derecho Penal, 6 (2006).

BUSATO, Paulo, Derecho penal y acción significativa. Un análisis de la función negativa del concepto de acción en Derecho Penal, Valencia: Tirant lo Blanch, 2007.

CARBONELL MATEU, Juan Carlos, "Sobre tipicidad e imputación: reflexiones básicas en torno a la imputación del dolo y la imprudencia", Estudios penales en recuerdo del profesor Ruiz Antón, OCTAVIO DE TOLEDO Y UBIETO; GURDIEL SIERRA;

CORTÉS BECHIARELLI (Coords.), Valencia: Tirant lo Blanch, 2004.

COBO DEL ROSAL, Manuel; VIVES ANTÓN, Tomás, Derecho Penal. Parte General, $5^{\text {a }}$ ed. Valencia: Tirant lo Blanch, 1999.

DAVIDSON, D. "Truth and Meaning", Synthese 17; 3, Language in Use Including Wittgenstein's Comments on Frazer and Symposium on Mood and Language Games (1967).

DAVIDSON, Donald, “Actions, Reason, and Causes”, Essays on Actions and Events, $2^{\mathrm{a}} \mathrm{ed}$. Oxford: Oxford University Press, 2001.

FAKHOURI GÓMEZ, Yamila, Delimitación entre error de tipo y de prohibición. Las remisiones normativas: un caso problemático, Pamplona: Thomson Reuters, 2009.

FEINBERG, Joel, "Action and responsibility", Essays in Theory of Responsibility, Princeton: University Press, 1970.

FERREIRA CABRAL, Rodrigo, Dolo y lenguaje. Hacía una nueva gramática del dolo desde la filosofía del lenguaje, Valencia: Tirant lo Blanch, 2017.

GEACH, P. “Ascriptivism”, The Philosophical Review, Vol. 69:2 (1960), pp. 221-225.

GONZÁLEZ LAGIER, Daniel, Acción y norma en G. H. von Wright, Madrid: Centro de Estudios Constitucionales, 1995.

GONZÁlEZ LAGIER, Daniel, Las Paradojas de la Acción, 2a ed., Madrid: Marcial Pons, 2013.

GRICE, H. P. "Meaning”, The Philosophical Review, 66; 3 (1957).

GRICE, H. P. "Utterer`s meaning, sentence- meaning, and word-meaning" The Philosophy of Language, ed. J. R. Searle, Oxford: Oxford University Press, 1977.

GRICE, H. P. "Utterer's meaning and intentions", The Philosophical Review, 78; 2 (1969), pp. 377-388.

HABERMAS, Jürgen, “Acción comunicativa y razón sin trascendencia”, Entre Naturalismo y Religión, Barcelona: Paidós, 2006.

HABERMAS, Jürgen, Facticidad y validez. Sobre el Derecho y el Estado democrático de Derecho en términos de teoría del discurso, JIMÉNEZ REDONDO (trad.), Madrid: Trotta, 2005. 
HACKER, P. M. S. "Davidson on Intentionality and Externalism", Philosophy 73 (1998), pp. 539-552.

HART H. L. A. "Punishment and Responsibility", Essays in the Philosophy of Law, $2^{\mathrm{a}}$ ed., Oxford: Oxford University Press, 2008.

HART, H. L. A. "The Ascription of Responsibility and Rights", Proceedings of the Aristotelian Society New Series, Vol. 49, (1948-1949), pp. 171-194.

HART, H. L. A., "Problems of the Philosophy of Law", Essays in Jurisprudence and Philosophy, Clarendon Press, Oxford, 1983.

HART, H.L.A; HONORÉ, Tony, Causation in the Law, $2^{\mathrm{a}}$ ed., Oxford: Clarendon Press, 1985.

HART, H.L.A., "Introduction", Essays in Jurisprudence and Philosophy, Oxford: Clarendon Press, 1983.

HIERRO S. PESCADOR, José. "En torno a la intencionalidad”, Revista de Filosofía, 14 (1994), pp. 29-44.

HONORÉ, A. M., "Real Laws", Law, Morality, and Society: Essays in Honour of H. L. A. Hart, P. M. S. Hacker and J. Raz (eds.), Oxford: Clarendon Press, 1977.

HRUSCHKA, Joachim, "Imputation”, BYU Law Review, 3 (1986).

HRUSCHKA, Joachim, Strukturen der Zurechnung, Berlín: Walter de Gruyter, 1976.

HSU, Yu-An, "Indiferencia como dolo indirecto", El sistema penal normativista en el mundo contemporáneo, Libro Homenaje a Günther Jakobs, Bogotá: Universidad Externado de Colombia, 2008, pp. 411-440.

JAKOBS, Günther, “Altes und Neues zum strafrechtlichen Vorsatzabegriff”, Rechtswissenschaft, 3 (2010), pp. 282-297.

KINDHAÜSER, Urs, “Der Vorsatz als Zurechnungskriterium”, ZStW, 96 (1984).

MACCORMICK, Neil; BANKOWSKI, Z., "Speech Acts, Legal Institutions, and Real Laws", The Legal Mind: Essays for Tony Honoré, N. MacCormick and P. Birks (eds.), Oxford: Clarendon Press, 1986.

MARTÍNEZ GARAY, Lucía, Proyecto docente e investigador (inédito), Valencia: Universidad de Valencia, 2004.

MIRÓ LLINARES, Fernando, "Dolo y derecho penal empresarial: debates eternos, problemas modernos", Cuadernos de Política Criminal, 113 (2014), pp. 201-252.

MOLINA, Fernando, "El razonable regreso del dolo a la culpabilidad", en: SILVA SÁNCHEZ, Jesús María, et al. (Coords.), Estudios de Derecho penal. Libro homenaje al profesor Santiago Mir Puig, Montevideo-Buenos Aires: B de F, 2017, pp. 735-751.

MORILLAS CUEVA, Lorenzo, "De nuevo sobre la doble posición del dolo y de la imprudencia" en: SILVA SÁNCHEZ, Jesús María, et al. (Coords.), MontevideoBuenos Aires: B de F, 2017, pp. 753-767.

MOYA, Carlos, J. Filosofía de la Mente, Valencia: PUV, 2004.

NINO, Carlos, Introducción a la filosofía de la acción humana, Buenos Aires: Eudeba, 1987.

PÉREZ BARBERÁ, Gabriel, El dolo eventual. Hacia el abandono de la idea del dolo como estado mental, Buenos Aires: Hamurabi, 2010.

PÉREZ MANZANO, Mercedes, "dificultad de la prueba de lo psicológico y naturaleza normativa del dolo", en: GARCÍA VALDÉS, et al. (Coords), Estudios Penales en Homenaje a Enrique Gimbernat, t. I, Madrid: Editorial Edisofer, 2008, pp. 14531486. 
PITCHER. G. "Hart on Action and Responsibility", The Philosophical Review 69, 2 (1960), pp. 226-235.

PORCIÚNCULA, José Carlos, Lo “objetivo" y lo "subjetivo" en el tipo penal. Hacia la "exteriorización de lo interno", Barcelona: Atelier, 2014.

PUPPE, Ingeborg, "La imputación del resultado al dolo", SILVA SÁNCHEZ, Jesús María, et al. (Coords.), Estudios de Derecho penal. Libro homenaje al profesor Santiago Mir Puig, Montevideo-Buenos Aires: B de F, 2017, pp. 803-811.

PUPPE, Ingeborg, El Derecho penal como ciencia. Método, teoría del delito, tipicidad y justificación, Montevideo-Buenos Aires: B de F, 2014.

PUTNAM, Hilary, Representación y realidad. Un balance crítico del funcionalismo, Barcelona: Gedisa, 2014.

RAMOS VÁSQUEZ, José Antonio Ramos Vásquez, José Antonio, Concepción significativa de la acción y teoría del delito, Valencia: Tirant lo Blanch, 2008.

RAMOS VÁSQUEZ, José Antonio, "Una aproximación wittgensteiniana al Derecho penal", Temas actuales de investigación en ciencias penales: memorias I Congreso Internacional de Jóvenes Investigadores en Ciencias Penales, Salamanca: Universidad de Salamanca, 2014.

RAWLS, John, "Two concepts of rules", The Philosophical Review, 64:1 (1955).

RAWLS, John, A Theory of Justice, The Belknap Press of Harvard University Press, Massachusetts: Cambridge, 1971.

RUSSELL, Bertrand, "V. Denotación", Los Principios de la Matemática. Ciencia y Filosofía (1897-1919), Obras Completas, t. II., Madrid: Aguilar, 1973.

RYLE, Gilbert, The Concept of Mind, London: Hutchinson`s University Library, 1951.

SÁNCHEZ MÁlAGA, Armando, Una teoría para la determinación del dolo. Premisas teóricas e indicadores prácticos, Montevideo-Buenos Aires: B de F, 2018.

SÁNCHEZ-VERA GÓMEZ TRELLES, Javier, "Un reto para el dolo: los motivos del autor", en: MAQUEDA ABREU, María Luisa; MARTÍN LORENZO, María; VENTURA PÜSCHEL, Arturo (coords.), Derecho penal para un Estado Social y Democrático de Derecho. Estudios penales en homenaje al profesor Emilio Octavio de Toledo y Ubieto, Madrid: Servicio de Publicaciones de la Facultad de Derecho de la Universidad Complutense de Madrid, 2016, pp. 339-363.

SEARLE, John, Intencionalidad. Un Ensayo en la Filosofía de la Mente, Ujaldón y Valdés (trad.), Madrid: Tecnos, 1992.

SEARLE, John, The construction of Social Reality, New York: Simons \& Schuster, 1995.

SEARLE, John. Rationality in Action, Massachusetts: A Bradford Book: The MIT Press, 2001.

SILVA SÁNCHEZ, Jesús María, “¿Adiós a un concepto unitario de injusto en la teoría del delito? A la vez, una breve contribución a la teoría de las medidas de seguridad", InDret, 3 (2014), pp. 1-24.

STRAWSON. P. F. "Intention and Convention in Speech Acts", en: SEARLE, J.R. (Ed.), The Philosophy of Language, Oxford: Oxford University Press, 1977, pp. 439460.

VARELA, Lorena, Dolo y error. Una propuesta para la imputación auténticamente subjetiva, Barcelona: Bosch, 2016.

VIVES ANTÓN, Tomás Salvador, Fundamentos del sistema penal. Acción significativay derechos constitucionales, 2 $2^{\text {a }}$ ed., Valencia: Tirant lo Blanch, 2011. 
VON WRIGHT, Georg, Norma y acción. Una investigación lógica, GARCÍA FERRERO (trad.), Madrid: Edtorial Tecnos, 1970.

WESSELS, Johannes; BEULKE, Werner; SATZGER, Helmut, Strafrecht AllgemeinerTeil. Die Straftat un ihr Aufbau, 44. Auflage, Heidelberg, München: C. F. Müller, 2013.

WINCH, Peter. The idea of a Social Science and its Relation to Philosophy, 2a. London: Routledge, 2003.

WITTGENSTEIN, Ludwig, Cuadernos de Azul y Marrón, Gracia Guillén (trad.), Madrid: Tecnos, 1976.

WITTGENSTEIN, Ludwig, Philosophical Investigations, Anscombe (trad.), London: A Blackwell Paperback, 1999. 